\title{
Crisis-driven innovation: The case of humanitarian innovation
}

\author{
John Bessant ${ }^{1}$, Howard Rush ${ }^{2}$, Anna Trifilova ${ }^{3}$ \\ ${ }^{1}$ University of Exeter, United Kingdom \\ ${ }^{2}$ University of Brighton, CENTRIM, United Kingdom. \\ ${ }^{3}$ University of Saint Petersburg, Universitetskay Nabereshnaya, \\ 7/9, Saint Petersburg, 199034, Russia
}

\begin{abstract}
Innovation is often presented as a survival issue and this provides a powerful metaphor to focus attention on the need to manage it effectively. But in the humanitarian context it takes on a very literal meaning. Crises, whether natural or man-made, require rapid problem solving if agencies and aid workers are to avoid the huge negative impacts of such disasters.

That makes consideration of how innovation takes place in this sector an urgent challenge. How can the humanitarian sector best organize to enable innovation and what are the roles for key actors - donors, agencies, and most importantly 'users'? Our paper summarizes the nature of the challenge and reviews experience so far in humanitarian innovation ( $\mathrm{HI})$.

There is a second issue which we also explore. Arguably crisis conditions provide a 'laboratory' for exploring alternative approaches and generating novel innovation trajectories which might diffuse more widely - the concept of 'reverse innovation'. Are there lessons which could be learned for mainstream innovation management? And if so, what are the mechanisms which might enable such learning and experience exchange to take place?
\end{abstract}

Keywords: humanitarian innovation; crisis-driven innovation; reverse innovation. 


\section{Humanitarian innovation}

Innovation is often presented as a survival issue and this provides a powerful metaphor to focus attention on the need to manage innovation and to update our capabilities to do so on a continuing basis. But in the humanitarian context it takes on a very literal meaning. Crises, whether natural or man-made, require rapid problem solving if agencies and aid workers are to avoid the huge negative impacts of such disasters; innovation in this context is often a life-or-death issue.

The importance of humanitarian innovation $(\mathrm{HI})$ should not be underestimated. As a recent United Nations report put it: '.... nearly 150 million people were affected by a combination of natural disasters, wars and conflicts in 2013, and the number of people needing assistance as a result has more than doubled over the last decade. International humanitarian agencies are already struggling to meet these growing and increasingly complex needs. Without concerted effort, the gap between what is needed and what is provided is likely to grow in the coming years and decades. ${ }^{1}$

Whilst $\mathrm{HI}$ has always taken place little formal attention was paid to how it was organized and managed until recently. Problem-solving under crisis conditions and ad hoc responses characterized the sector as distinct from a more planned and prepared approach which sought to learn from prior experience and develop more effective models. One indicator of this was that in the literature related to the humanitarian sector there were no publications focused on the subject until 2009 (Bessant, Rush et al. 2014).

${ }^{1}$ UN OCHA (2015). World Humanitarian Data and Trends 2014, New York. 
A key study was published in that year by ALNAP $^{1}$ which attempted a definition and offered a suggested framework for HI, drawing on a series of case studies as illustrations and building on relevant literature (Ramalingam, Scriven et al. 2010). That study closed with a framework for humanitarian innovation showed that innovation forms and processes were embedded in three supporting areas:

- Capacities, including those of innovation entrepreneurs and leaders; field and operational staff; researchers and evaluators, and external experts;

- Relationships, including with affected populations, within aid agencies, between international and national actors, with researchers and academics, with the private sector, and between operational agencies;

- Contextual factors relating to the sector, including culture of risk, financing, codes and standards and incentives.

The study also showed that the turning point in innovation management involved not just a series of windows of opportunity for a new idea or practice, but also serious constraints on the existing standard operating procedures, so that there was little choice but for a new approach to be attempted. ALNAP's work was used to support the founding of the Humanitarian Innovation Fund (HIF), an agency with the remit to provide both a funding route for entrepreneurial ideas in the $\mathrm{HI}$ space and also to raise awareness and build capacity in the field.

Since the publication of the ALNAP report there has been a growing interest in the $\mathrm{HI}$ theme and an increase in publications - for example, the Humanitarian Emergency Response Review of the UK Government's aid efforts (DFID 2011). HI research involves multiple themes - for example, the University of Oxford's Humanitarian Innovation Project (OxHIP) highlights the need for more bottom-up, user driven innovation especially amongst refugee groups (Betts and Bloom 2014). Medecins sans Frontieres (MSF) took a sectoral perspective in their review of medical innovations (Bradol and Vidal 2011). In 2012 the HIF

1 The Active Learning Network for Accountability and Performance in Humanitarian Action was established in 1997 as a mechanism to provide a forum on learning, accountability and performance issues for the humanitarian sector. See www.alnap.org for more information. 
commissioned a review of the gaps in emergency water and sanitation that would be the focus of targeted innovation management processes and The Shelter Centre has convened similar research in emergency shelter.

Over the past six years there has been steady acceleration in interest and a shift in attention to the humanitarian innovation system as a whole. The issue is now high on the agenda - for example the 2016 United Nations World Humanitarian Summit will spend much of its time focusing on the innovation question. In particular attention is moving from recognizing the importance of sustained innovation to thinking about how best might we organize and manage it?

Overall, innovation practices appear to be slowly evolving: for example, the growing use of design-led approaches in public, social and development innovation is now diffusing into the humanitarian sector. User-led innovation is another key theme, for example with front-line workers and sometimes aid recipients themselves being involved in innovation processes ${ }^{1}$.

\section{Research design and methodology}

This paper reports on progress so far in a project funded by the UK's Department for International Development (Ramalingam, Rush et al. 2015). It draws upon a literature review (Bessant, Rush et al. 2014), an extensive (and continuing) series of interviews with over 50 key stakeholders in the humanitarian innovation (HI) system and on a series of detailed case studies in five key sectors dealing with food, water and sanitation, healthcare, shelter and the underlying financing of $\mathrm{HI}$.

In this work we are using a framework for analysis exploring key resources, roles, relationships and routines, and a systems map as a means by which the different elements and interactions (invention, development and adoption of innovations) of the $\mathrm{HI}$ ecosystem can be better understood (Lundvall 1990; Nelson 1993; OECD 1997).

\footnotetext{
${ }^{1}$ An example is the UK AMPLIFY project, conducted with support from IDEO. See https://www.gov.uk/international-development-funding/amplify-collaborative-challengefund for more.
} 
Research has been based on secondary sources and interviews with key players in the field, using a snowball approach in which respondents are asked to nominate others who could contribute useful perspectives. Building upon the interview survey referred to above, the case studies included over 200 in-depth interviews with technical experts, service providers, managers, researchers, etc., in each of the respective humanitarian sub-sectors covered in the case studies.

Our research questions in this project can be summarised as:

- What is the current 'state of the art' regarding humanitarian innovation?

- What lessons might usefully be transferred from wider innovation management experience?

- What lessons might the $\mathrm{HI}$ system contribute to that wider experience?

We will explore our early findings in respect of these questions in the following sections.

\section{Patterns in humanitarian innovation - the current 'state-of-the-art' ${ }^{1}$}

Although not formally studied until recently $\mathrm{HI}$ operates in ways which can be mapped to existing models of innovation management. There is a 'market' whose needs are articulated by a variety of agencies and actors, and innovations are developed to try and meet those needs. There is a much less well-developed 'R\&D' system which generates solutions in proactive fashion, and then tests and improves them in the field; funding for this aspect of $\mathrm{HI}$ is limited and concentrated mainly in the hands of donors who tend to be risk-averse (in part because they are acting as stewards for public and donated monies). The resulting innovation

\footnotetext{
${ }^{1}$ A more detailed discussion of the $\mathrm{HI}$ innovation ecosystem can be found Rush, H., J. Bessant, B. Ramalingam, I. Gray, W. Gray, K. Hoffman and N. Marshall (2015). Strengthening the humanitarian innovation system. Brighton, CENTRIM, University of Brighton.
} 
system tends to follow clearly established aid trajectories within which incremental 'sustaining' innovations take place rather in the fashion of large companies in mature markets. At the same time there is considerable experimentation at the edges of this system, often involving entrepreneurs working in close collaboration with end users and evolving novel solutions to $\mathrm{HI}$ crises. Activity here approximates to the early stage learning and experimentation at the fringe which characterises emergent disruptive innovation in Christensen's analysis (Christensen 1997). But for many interesting innovations which emerge here there is the major problem of moving to scale, of developing and testing solutions which are robust enough to be widely deployed and which do not challenge existing delivery agencies (McClure and Gray 2015).

The result is a tension between two parallel and potentially complementary innovation models - one concerned with incremental improvements along a dominant design trajectory and the other offering radical solutions but often lacking the traction to move to the mainstream.

These are, of course, familiar patterns in the wide innovation literature. They echo the extensive discussion of 'ambidexterity' within large organizations, the need for internal venturing and corporate entrepreneurship and the challenges posed by turbulent uncertain environments with attendant risks of disruption (Kuratko, Hornsby et al. ; Tushman and O'Reilly 1996; Augsdorfer, Bessant et al. 2013; Martini, Neiretti et al. 2015). It will be useful to explore a particular case in a little more detail since it highlights these two parallel innovation strands.

\section{A case example - cash-based programming in food assistance}

\section{Early days}

Although there are many early examples of food aid the origins of a systematic and large-scale response can probably be dated back to the 1950s. A combination of accumulated surpluses in developed countries 
like the US and the EEC and the desperate plight of many in famineafflicted areas led to the development of food aid programmes. In 1963 the World Food Programme (WFP) was formed as a UN agency with the mission of eradicating hunger and malnutrition.

A supply and distribution ecosystem emerged with major agencies like WFP linking donors of money and food with large non-governmental organization (NGO) delivery partners (like World Vision, CARE and Oxfam) handling distribution. By the 1970s the systems for delivering such aid were well-developed and there was extensive innovation supporting the core mechanisms in place. Process innovation focused on improving warehousing and consolidation, on transport and logistics and on distribution management. Product innovation included work on improving nutritional value and 'position innovation' (Francis and Bessant 2005) was concerned with extending the range of targets towards which aid could be delivered and learning and adapting systems for those contexts.

The 1980s - gradually changing the pattern

The 1980s saw a gradual shift in approach, in part triggered by the decline in agricultural surpluses in the developed countries and in part by recognition that local markets could often be a viable source of supply (Barrett and Maxwell 2005). There was also growing concern that large food aid deliveries had a depressing effect on local markets. Emphasis shifted towards procurement rather than delivery and this period saw a move towards internal or regional purchases to stimulate markets. Agencies like WFP began to receive an increasing proportion of donations in the form of money rather than kind and this shift created a need for new capabilities and infrastructure - for example in monitoring prices and suppliers on the international market and brokering aid delivery.

In parallel a small number of experiments with a radical alternative were taking place using cash directly to enable the purchase of food on local markets. These emerged for many reasons - sometimes (as in the Eritrea crisis) it became dangerous to ship food because convoys were attacked. Instead mechanisms evolved to allow surreptitious movement of money to crisis zones to enable some form of food assistance to be provided. There was also growing recognition that even if food was provided as aid 
recipients would sometimes trade this on local markets for things which they needed more - in essence food was being used as a currency with which to procure other supplies of goods or services.

The idea behind this was not new - for example, Clara Barton, one of the founding figures of the American Red Cross, helped to organize cash relief following the Franco-Prussian War of 1870-71 and similar programmes were organized in response to the Galveston floods in Texas in 1900 (Harvey 2007). In 1948 the British administration's response to the famine in Sudan was to distribute cash, coffee and train tickets and in India they responded to famines by providing waged labour (Keen 1992). Cash relief interventions were also implemented in famines in Tanganyika (now Tanzania), Rhodesia (now Zimbabwe) and colonial China (Dreze and Sen 1989).

There was also discussion around the theoretical ideas of cash vs. food aid going back to the 1970 s but whilst the principle was recognized it was not until the mid-1980s that actual experiments with the practice began (Gentilini 2007). These were very much isolated bottom-up pilots, pioneered by entrepreneurial agents working in the field and taking advantage of local autonomy to explore novel approaches. The individuals involved were loosely connected in an informal network and so some degree of experience-sharing and accumulation of core models for cash-based programming began to emerge.

\section{The 1990s - further experimentation}

The 1990s involved a limited expansion of experimentation, with a number of models being tried in different locations. All shared the idea of moving away from direct delivery of food aid and towards using cash as a way of empowering local players to procure what they needed. Examples included programmes tied to specific objectives like cash for work through to more open-ended schemes and different modalities were tried, ranging from vouchers and cards to direct cash payments (NORAD 2011).

These experiments also highlighted challenges in establishing a viable cash model. For example, issues of distribution and control, of security and of developing an underpinning infrastructure in terms of technology 
and skills. There was also a need to improve understanding of the ways in which local markets operated in order to avoid distorting effects from cash interventions.

One other important factor in the 1990s was the growing understanding of the context within which food and other assistance was being place (Chambers and Conway 1991). In particular the Vulnerability Assessment Method and other approaches began to influence the ways in which major agencies like WFP and delivery NGOs like Save the Children and CARE began to operate(Moret 2014). Tools for assessment of needs became sharper and more sophisticated, allowing assistance to be more carefully targeted and matched. Part of this development involved growing recognition of end-recipients as active agents in the aid process.

The early 2000s - Maturing of the concept

By 2001 considerable evidence from ten years of small-scale experiments had accumulated demonstrating the solid case for considering cash programming as an option in food assistance (Peppiat, Mitchell et al. 2001). This brought the potential of this radical innovation to the attention of senior policy-makers (Harvey 2005) and key networks like the Humanitarian Policy Group began to shape the discussion and provide a focus for sharing of evidence and experience. Early advocates pressed for more exploration and the agenda was beginning to shift from "should we work with cash?" to "how do we work with cash?". But despite growing interest and activity - particularly amongst early adopters like Oxfam, British Red Cross, DFID, Adeso or the Swiss Development Corporation - the overall level of activity was still low.

For example a report for ODI in 2005 commented that "cash and voucher approaches remain largely underutilised in the humanitarian sector. A review of all of the 2004 United Nations consolidated appeals, .... reveals almost no use of cash or vouchers." (13).

During this period considerable learning took place about the challenges of designing and implementing viable cash systems. The need for new skills and knowledge, the potential of new technologies and the opportunities opened up by a change in the underlying dominant logic of food assistance were increasingly recognized and explored. And the 
concept moved from a 'one size fits all' model to an increasingly configurable one, shaped to meet different operating contingencies.

2004 - the 'tipping point'

The huge scale of the 2004 Tsunami crisis prompted a massive response and a significant injection of resources into the humanitarian aid system. Combined with negligible damage to food production and marketing systems beyond the immediate coastal areas this sparked widespread experimentation with and evaluation of cash and vouchers as alternatives to in-kind food deliveries.

Major cash-based programmes were implemented in a variety of locations, offering opportunities for learning and refining the approach. The crisis acted as a prism through which the idea of cash programming became diffracted, spreading out in terms of operating models, delivery systems, target populations and enabling technologies. Some were centralized and linked to large-scale formal programmes like cash for work whilst others were bottom-up, configured with considerable input from end-users. Some were food-focused; others linked their programmes to a wider set of needed resources including shelter. This was an important phase in the maturing of the concept since it highlighted the importance of a deep understanding of context in designing, configuring and implementing effective programmes.

The Tsunami experience accelerated mainstream adoption of the CBP approach. A 2005 review by the UK Overseas Development Institute (ODI) (Harvey 2005) concluded that:

" ... a strong body of evidence is starting to emerge to indicate that providing people with cash or vouchers works. It is possible to target and distribute cash safely, and people spend money sensibly on basic essentials and on rebuilding livelihoods. Cash transfers can provide a stimulus to local economies, and in some contexts can be more cost-effective than commodity-based alternatives...."

The field was maturing with evidence about many different contexts (for example cash tools were used in the Hurricane Katrina and German flood 
contexts (Harvey 2007)) and the emergence of policy tools such as checklists to help target where, when and in what form CBP would be appropriate.

An important contribution here was the role of CaLP - the Cash Learning Partnership. The origin of this group was an informal experience sharing network collating and curating the emerging body of knowledge around cash programming. It was formalised in 2005 with Oxfam, Save the Children and the British Red Cross as founders and has grown to be a key institution in the humanitarian innovation landscape supporting capacity building, research and information sharing ${ }^{1}$.

In parallel with this the range of technological options to enable cash programming had expanded, especially with the growing use of mobile money across cellular phone networks. The experience of M-PESA in Kenya opened a wide range of new complementary possibilities around how cash systems could be quickly established and operated (Datta, Ejakait et al. 2009).

\section{0 - moving to scale}

Further impetus was given to the use of cash in the aftermath of the Haiti earthquake in 2010. This was characterized by a very high level of cashbased interventions; local food markets began functioning soon after the disaster and the government stopped food distribution interventions after only three months. However the lack of formal distribution systems (such as ATMs and key parts of the physical banking infrastructure) meant an upsurge in alternative methods of cash distribution. Some were low tech involving human agents or physical collection at bank branches but there were limits to the scale and location of these operations, especially in rural areas. For this reason cash transfers enabled by mobile phone were widely adopted, demonstrating the considerable potential of such approaches in rapidly setting up and scaling viable systems (MacDonald and Gedeon 2012).

During the past five years the expansion has continued, both in CBP projects themselves and in learning around specific aspects of the approach - for example about delivery mechanisms (Harvey and Bailey

\footnotetext{
${ }^{1}$ For more details see their website: http://www.cashlearning.org/
} 
2010), gender (Brady 2011), scaling up (Austin and Frize 2011), nutritional impact (Bailey and Hedlund 2012) and comparative impacts of food aid and cash transfers (Hidrobo, Hoddinott et al. 2012); Hoddinott et al., 2013 (Hoddinott, Sandstrom et al. 2013), (Schwab 2013),(Gilligan, Margolies et al. 2013). The response to the 2011 Somalia famine was significant because it effectively broke the scale barrier - it was the first time that international aid agencies used cash and vouchers at scale in a humanitarian response with an estimated $\$ 77 \mathrm{~m}$ committed in this form by 2012.

Major agencies have made substantial changes in their delivery programmes - for example, between 2008 and 2011 WFP increased its CBP portfolio by a factor of ten, from 5 projects to 51 . Its 2008-2013 strategic plan stated the intention to provide $30-40 \%$ of its assistance in the form of cash and vouchers by 2015. Another signal of the acceptance of cash is the Food Assistance Convention. Through this international treaty, which entered into force in January 2013, countries commit to providing certain amounts of annual food assistance. But unlike its predecessor (the Food Aid Convention), food aid is no longer the only tool through which countries can achieve their commitments; cash and vouchers are considered as contributions. Figure 1 summarizes the key features of this brief history. 


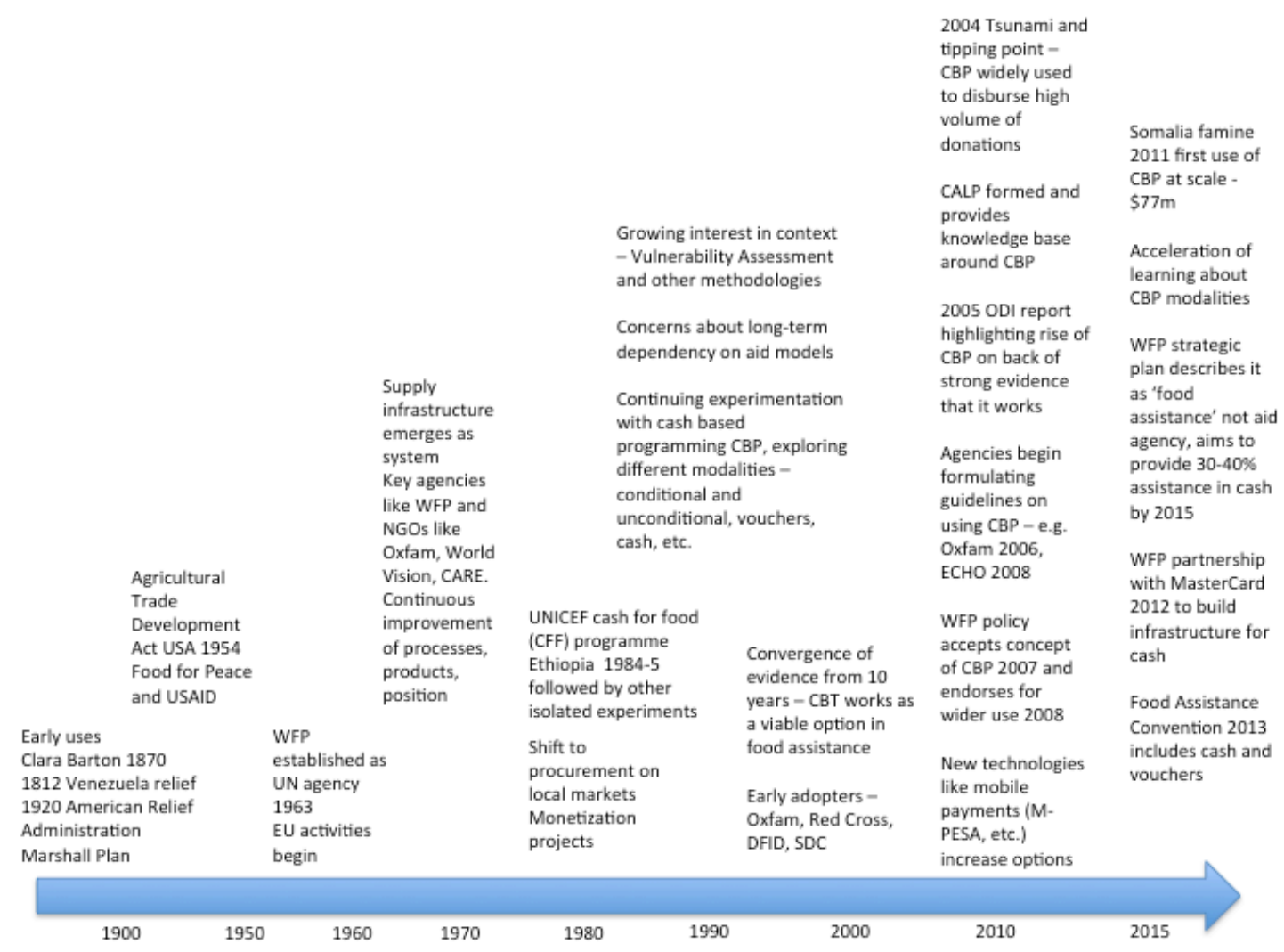

Source: Developed by authors.

Figure 1 Key points in the food aid/relief timeline.

\section{Learning for the $\mathrm{HI}$ sector}

Innovation theory provides a number of lenses through which to interpret this case and provide insights into the workings of the humanitarian innovation ecosystem. For example the Abernathy/Utterback model of innovation life cycles highlights the ways in which a dominant design becomes embedded in a mature system and the role played by entrepreneurs in challenging it, recreating a fluid state from which a new dominant design emerges (Abernathy and Utterback 1975). Another helpful lens is Christensen's theory of disruptive innovation which sees radical innovation emerging at the fringes of the mainstream, driven by entrepreneurs experimenting and learning in that 
space (Christensen 1997). Early problems are solved and the innovation develops in maturity until it becomes attractive to mainstream markets at which point it poses a challenge to existing incumbents.

The process is one of fast failure and learning, gradually refining key elements of the innovation in the context of application. Recent models of agile innovation build on this, using concepts like rapid prototyping, minimum viable product, scrum teams and sprints to define a set of tools which enable fast cycles of experimentation and learning (Blank 2013; Breuer 2013; Morris, Ma et al. 2014).

In the case of cash programming this was very much the observed pattern with small-scale entrepreneurial activity refining and defining a new model via a process of controlled experimentation with different delivery models, technologies and other elements. In particular the process took place at a time of rapid technological change where new developments (such as mobile payments and better online security) facilitated the building of a carrier infrastructure for cash programming.

The evidence base grew to a point where original objections were overcome - for example about whether end users could be trusted, how to avoid corruption, maintain security, etc. We can map this on to a classical S-curve and explain many of the features around slow take-up and then acceleration in terms of diffusion theory (Rogers 2003). In particular slow take-up and early resistance is not simply a matter of mindset although this is a powerful inertial force. Henderson and Clark's theory of architectural innovation highlights the big challenge to the underlying structures and competencies required to implement radically new models which requires both learning new ways of working and simultaneously letting go of old but no longer relevant approaches (Henderson and Clark 1990). Cash programming requires a new technological infrastructure with different skills, moving away from a supply and distribution model to one resembling more closely a financial system. It also moves from a centralized mode towards a decentralized network model, with corresponding shifts in power and influence.

Arguably cash programming represents a paradigm shift in the underlying mental models around food; this is reflected in the change of terminology from food aid to food assistance. This has required considerable 
adaptation on the part of mainstream incumbents and challenged much in the way of established structure and practice.

The case highlights the existence of an innovation ecosystem within the humanitarian sector and the challenges of managing innovation at this level. There are key players and institutions and connectivity across a network which supports what Christensen calls sustaining innovation effectively doing what we do but better. But there are also points where experimentation takes place and new, radical options emerge; these tend to be at the fringes of the mainstream system and not well integrated, often driven by individual entrepreneurs acting in maverick mode. They have greater flexibility to experiment, uninhibited by the biases, standard operating procedures, bureaucracy, cultures, strategic commitments, and other rigidities common in established organizations of all kinds.

Finding ways to couple these two systems - the mainstream do better machine with its advantages of scale and the entrepreneurial fringe with its capacity for radical new thinking - is a significant challenge for the ecosystem in the future. Ambidexterity also places emphasis on the role of users in context who can help shape and configure innovations so that they are suitable for wider diffusion; the process is essentially one of coevolution. There is also considerable opportunity within the sector for more open approaches to innovation, especially in cross-sector learning. The significant contribution of financial sector professionals and institutions to enabling the radical shift in infrastructure is a good example where such collaboration can accelerate change.

\section{Learning from the $\mathrm{HI}$ sector}

Our third research question - what can the $\mathrm{HI}$ sector offer as new insights for mainstream innovation management? - highlights the potential for seeing $\mathrm{HI}$ as a 'crisis laboratory' for stimulating novel thinking. Innovation in this context is often radical in nature because the existing set of solutions to problems are closed off. Research - for example the ALNAP study mentioned earlier - shows that the turning point in innovation management involves not just a series of windows of opportunity for a 
new idea or practice, but also serious constraints on existing standard operating procedures. Faced with this roadblock there is often little choice but to try a completely new approach.

In particular such crisis - driven innovation is characterized by

- Extreme conditions forcing a radical rethink of solution approaches, potentially opening up new innovation trajectories

- Users and context are critical - HI requires user participation in configuring solutions

- Rapid prototyping and learning are a key feature, $\mathrm{HI}$ is linked to entrepreneurial experimentation

- Rapid diffusion- a combination of urgency of need, configuration of appropriate solutions by engaged users and resource backing form major aid agencies to drive adoption to scale

- Recombination - the failure of existing solutions under crisis conditions forces a rethink and wider search space, opening up potential for cross-sector learning

Arguably these conditions provide a 'laboratory' for exploring alternative approaches and generating novel innovation trajectories which might diffuse more widely - the concept of 'reverse innovation' (Govindarajan, Trimble et al. 2012).

As a source of radical innovation, a way of breaking with dominant designs and established trajectories, $\mathrm{HI}$ represents an important approach which may have wider potential. (Significantly some organizations report making use of 'constructed crises' as an aid to moving into new mindsets and generating space for radical innovation paper (Kim 1998)).

So how might a process of systematic learning from crisis innovation operate? Table 1 sets out an outline process model involving several linked stages. Crisis conditions set stretch targets and force search 
behaviour in new directions; they also cue attentional responses to new signals rather than filtering them out. In the $\mathrm{HI}$ cases the ability to find a passionate entrepreneur at the centre may not be coincidence - their role is to have the vision but also the passion to infect others and bring them into the vision.

Exploration of potential new directions involves an 'observatory' stage, in which search behaviour is enabled in novel ways. This corresponds to open innovation search patterns and may well require brokerage, crosssector linkages, working with users, foresight, ethnography and multiple other approaches and often involves deliberate recruitment of outsiders to bring alternative experience and perspectives. It also requires the ability to abstract the core problem to a higher level such that potential solutions in other sectors/worlds can be perceived as relevant.

The 'laboratory' stage involves experimentation with the original idea to adapt it to the new context. By its nature this process involves failure and fast learning and user input is critical in shaping and configuring a robust solution. Whilst the initial idea may be radical its shaping and development involves integrating a wide range of small scale incremental improvements in a process of experimentation, learning, capture and codification.

In the 'prototype' stage there is further need for high user engagement and development of robust configurations which will actually work and be accepted. At this stage it is important to have a working model of the system level innovation which can act as a boundary object demonstrating the operation and advantages of the new approach but also allowing input from potential adopters in further shaping and developing the ideas.

Table 1 Suggested process model for working with crisis-driven innovation.

Stage Characteristic activity




$\begin{array}{ll}\text { Crisis } & \text { Creation of a driving entrepreneurial } \\ \text { vision which simultaneously articulates } & \text { the need for change and for radically } \\ \text { different solution involving anew } & \text { trajectory } \\ & \text { Extensive search in novel directions to } \\ & \text { find relevant approaches which could be } \\ & \text { adapted - requires ability to abstract } \\ \text { Observatory } & \text { higher level and brokerage mechanisms } \\ & \text { to make connections } \\ \text { Experimentation around core ideas and } \\ \text { creating in context a new system } \\ \text { through recombination of proven } \\ \text { elements from elsewhere } \\ \text { Development of a scale version of the } \\ \text { system which allows for testing and } \\ \text { configuration in context with users. Also } \\ \text { provides a boundary object which can } \\ \text { demonstrate potential and engage key } \\ \text { agents in further development and } \\ \text { diffusion } \\ \text { Codification of core model into a } \\ \text { standard transferable package which can } \\ \text { be replicated. Importantly this allows for } \\ \text { further innovation and continuous } \\ \text { improvement via channels which } \\ \text { integrate emerging ideas into the } \\ \text { standard operating model }\end{array}$

Source: Developed by authors.

Finally widespread diffusion depends on the codification of the new system into a transferable model. This does not mean that further innovation will not take place; indeed it is characteristic of the examples given that continuous improvement is embedded in their design. But the 
basic model has become standardized and codified to the point that it can be handed on to others who have not had direct experience and sufficient detail of the standard operating mode available to enable them to set up and operate in a different context. This part of the process is assisted by the fact that users and players have been involved in cocreating and especially configuring the model.

Mobilising this kind of approach poses challenges for established organizations but might usefully form part of the remit and operating model for corporate venturing units looking to facilitate 'out of the box' thinking on behalf of their organizations. Examples include Vodafone's involvement in the evolution of mobile payments in the M-PESA system in Kenya, Novo-Nordisks's exploration of the challenges in evolving a diabetes care service programme in Tanzania, UPS's work on 'extreme logistics' in post-disaster situations and the MasterCard/World Food Programme alliance described earlier.

But it also raises questions about 'ambidexterity' of the kind discussed earlier since the kind of project originating in such a 'crisis laboratory' may well challenge existing trajectories and their supporting structures; we saw an example of this in the food aid case. Successful integration of insights generated by it will depend on effective bridging mechanisms to ensure novel ideas are communicated, absorbed and deployed. In this respect the challenge is one of developing 'absorptive capacity' - building routines which allow not only for external search but also selection (bypassing the 'corporate immune system' (Bessant, Von Stamm et al. 2011)), assimilation and exploitation (Zahra and George 2002.). Further exploration on this boundary crossing challenge in open innovation will be an important future research priority (Newey 2010; Heil and Enkel 2015).

\section{References}

Abernathy, W. and J. Utterback (1975). "A dynamic model of product and process innovation." Omega 3(6): 639-656.

Augsdorfer, P., J. Bessant, K. Moeslein and B. Von Stamm (2013). Discontinuous innovation. London, Imperial College Press. 
Austin, L. and J. Frize (2011). Ready or Not? Emergency Cash Transfers at Scale. London, CaLP Cash learning Partnership.

Bailey, S. and K. Hedlund (2012). The impact of cash transfers on nutrition in emergency and transitional contexts A review of evidence. London, ODI.

Barrett, C. and D. Maxwell (2005). Food Aid After Fifty Years Recasting Its Role. New York, Routledge.

Bessant, J., H. Rush, W. Gray, K. Hoffman, B. Ramalingam and N. Marshall (2014). Innovation Management, Innovation Ecosystems and Humanitarian Innovation. London, DFID.

Bessant, J., B. Von Stamm, K. M. Moeslein and A.-K. Neyer (2011). "Backing outsiders: selection strategies for discontinuous innovation." R\&D Management 40(4): 345-356.

Betts, A. and L. Bloom (2014). Humanitarian Innovation: The State of the Art. Geneva, Oxford Humanitarian Innovation Project.

Blank, S. (2013). "Why the Lean Start-Up Changes Everything." Harvard Business Review 91(5): 63-72.

Bradol, J. and C. Vidal (2011). Medical Innovations in Humanitarian Situations

The Work of Médecins Sans Frontières. New York, MSF USA (Originally published in France as Innovations médicales en situations humanitaires: La travail de Médecins Sans Frontières by L'Harmattan).

Brady, C. (2011). Walking the Talk: Cash transfers and gender dynamics. London, OXFAM.

Breuer, H. (2013). "Lean venturing: learning to create new business through exploration, elaboration, evaluation, experimentation, and evolution

." International Journal of Innovation Management 17(3).

Chambers, R. and G. Conway (1991). Sustainable Rural Livelihoods: Practical Concepts

for the 21st Century.". Brighton, Institute of Development Studies. Discussion Paper 296.

Christensen, C. (1997). The innovator's dilemma. Cambridge, Mass., Harvard Business School Press.

Datta, D., A. Ejakait and K. Scriven (2009). Cash Transfersthrough Mobile Phones: An

Innovative Emergency Response in Kenya. London, ALNAP. 
DFID (2011). Humanitarian Emergency Response Review. London, Department for International Development (DFID)

Dreze, J. and A. Sen (1989). Hunger and Public Action. Oxford, Clarendon Press.

Francis, D. and J. Bessant (2005). "Targeting innovation and implications for capability development." Technovation 25(3): 171-183.

Gentilini, U. (2007). Cash and Food Transfers: A Primer. Rome, World Food Programme.

Gilligan, D., A. Margolies, E. Quinones and R. Shalini (2013). Impact Evaluation of

Cash and Food Transfers at Early Childhood Development Centers in Karamoja, Uganda. Washington, IFPRI.

Govindarajan, V., C. Trimble and P. Dubois (2012). Reverse Innovation: Create Far From Home, Win Everywhere. Boston, Harvard Business School Press.

Harvey, P. (2005). Cash and vouchers in emergencies. London, Humanitrian Policy Group, ODI.

Harvey, P. (2007). Cash based responses in emergencies. London, Humanitarian Policy Group , ODI.

Harvey, P. and S. Bailey (2010). Cash transfer programming in emergencies, Good Practice Review. London, Overseas Development Institute (ODI).

Heil, S. and E. Enkel (2015). "Exercising opportunities for crossindustry innovation: how to support absorptive capacity in distant knowledge processing." International Journal of Innovation Management forthcoming.

Henderson, R. and K. Clark (1990). "Architectural innovation: The reconfiguration of existing product technologies and the failure of established firms." Administrative Science Quarterly 35: 930.

Hidrobo, M., J. Hoddinott, A. Peterman, A. Margolies and V. Moreira (2012). Cash, Food, or Vouchers?

Evidence from a Randomized Experiment in Northern Ecuador. Washington, International Food Policy Research Institute (IFPRI)

Hoddinott, J., S. Sandstrom and J. Upton (2013). Impact Evaluation of Cash and Food Transfers in Zinder, Niger:

Analytical Report. Washington, WFP/ IFPRI. 
Keen, D. (1992). Providing an Income: The Other Side of the Relief Coin'. London, Zed Books.

Kim, L. (1998). "Crisis Construction and Organizational Learning: Capability Building in Catching-up at Hyundai Motor." Organization Science 9: 506-521.

Kuratko, D. F., J. S. Hornsby, D. W. Naffziger and R. V. Montagno "Implementing entrepreneurial thinking in established organizations." S.A.M. Advanced Management Journal 58(1): 28.

Lundvall, B. (1990). National systems of innovation: Towrads a theory of innovation and interactive learning. London, Frances Pinter.

MacDonald, B. and H. Gedeon (2012). Banking With Mobile Phones in Haiti - A report on a T-Cash pilot project. London, ALNAP.

Martini, A., P. Neiretti and D. Aloini (2015). "Finding the way to ambidexterity: exploring the relationships among organisational design, knowledge creation and innovation

." International Journal of Innovation Management 19(4).

McClure, D. and I. Gray (2015). Scaling: Innovation's missing middle. Online https://thoughtworks.fileburst.com/articles/scalinginnovations-missing-middle-dan-mcclure-ian-gray.pdf, Thoughtworks.

Moret, W. (2014). Vulnerability Assessment Methodologies: A Review of the Literature. Washington, USAID.

Morris, L., M. Ma and P. Wu (2014). Agile Innovation: The Revolutionary Approach to Accelerate Success, Inspire Engagement, and Ignite Creativity. New York, Wiley.

Nelson, R. (1993). National innovation systems: A comparative analysis. New York, Oxford University Press.

Newey, L. (2010). "Wearing different hats: how absorptive capacity differs in open innovation." International Journal of Innovation Management 14(4).

NORAD (2011). We accept cash: Mapping study on the use of cash transfers in Humanitrian recovery and transitional response. Oslo, Norwegian Agency for Development Co-operation.

OECD (1997). National innovation systems. Paris, Organization for Economic Co-operation and Development.

Peppiat, D., J. Mitchell and P. Holzmann (2001). Cash transfers in emergencies:

evaluating benefits and assessing risks. London, ODI. 
Ramalingam, B., H. Rush, J. Bessant, N. Marshall, W. Gray, K. Hoffman, I. Gray, S. Bayley and K. Warren (2015). Stengthening the humanitarian innovation ecosystem. Brighton, University of Brighton/ DFID

Ramalingam, B., K. Scriven and C. Foley (2010). Innovations in international humanitarian action. London, ALNAP.

Rogers, E. (2003). Diffusion of innovations. New York, Free Press.

Rush, H., J. Bessant, B. Ramalingam, I. Gray, W. Gray, K. Hoffman and N. Marshall (2015). Strengthening the humanitarian innovation system. Brighton, CENTRIM, University of Brighton.

Schwab, B. (2013). In the form of bread? A randomized comparison of cash and

food transfers in Yemen. Washington, IFPRI WFP.

Tushman, M. and C. O'Reilly (1996). "Ambidextrous organizations: Managing evolutionary and revolutionary change." California Management Review 38(4): 8-30.

Zahra, S. A. and G. George (2002.). "Absorptive capacity: A review, reconceptualization andextension." Academy of Management Review, 27:: 185-194. 